\title{
Prevalence and Polymorphism in Interferon- $\gamma$ Gene (CA) Repeats with Different Stages of Endometriosis
}

\author{
Venkanna Bhanothu ${ }^{1,2, *}$, Roya Rozati ${ }^{2}$, Jane Theophilus ${ }^{1}$ \\ ${ }^{1}$ Department of Zoology, UCS, Osmania University, Hyderabad, India \\ ${ }^{2}$ MHRT Hospital \& Research Centre, Hyderabad, India \\ *Corresponding author: venkanna_82@yahoo.co.uk
}

Received December 15, 2012; Revised February 08, 2013; Accepted February 15, 2013

\begin{abstract}
Background

Endometriosis is a female physical disorder that happens when cells from the lining of the womb (uterus) grow in other areas of the body i.e., outside of uterine cavity and leads to infertility. It represents a major personal and public health concern. The aim of the study was to investigate the prevalence and interferon-gamma gene CA-repeats polymorphism in patients with different stages of endometriosis.

Methodology/Principal Findings

It is a case control prevalence study carried out in gynecology research centre. The mutational analysis of Interferon$\gamma$ gene CA repeats were tested for association in 356 affected women with different stages of disease and 372 women with no evidence of disease. The prevalence of endometriosis was accounted in $44.95 \%$ of infertile women. All the women were of South Indian origin and ascertained from the same infertility clinic. The broad IFN-gamma genotype and allele frequencies in all patients with different stages of endometriosis varied significantly from that in the control women $\left(\chi^{2}=8.2690,4 \mathrm{df}, \mathrm{P}=0.0822\right)$. The disparity in distribution was due to an increase in the a13 $(114 \mathrm{bp})$ allele in the patients with endometriosis $\left(\chi^{2}=13.2394, \mathrm{p}=0.00027, \mathrm{OR}=1.6656,95.0 \% \mathrm{CI}=1.263-2.1953\right)$.

Conclusions/Significance

Significant difference was experiential in universal allele frequencies between the control women and specifically, women with endometriosis staging were tilted in the direction of minimal (39.04\%) and mild disease (33.98\%). Therefore, we conclude that interferon-gamma CA-repeat polymorphism may influence the likelihood of a woman developing different stages of endometriosis irrespective of its incidence.
\end{abstract}

Keywords: Different stages of endometriosis, Prevalence, Interferon- $\gamma$ gene polymorphism

\section{Introduction}

Endometriosis is defined as the presence and growth of endometrial tissues outside the uterus, which impair fertility, [1,2] and the disease has a strong genetic component $[3,4]$. It affects $10-32 \%$ of women of fertile age, causing pelvic pain and infertility [5,6]. It is a benign disease but it can behave like a malignancy in terms of growing, infiltrating, adhering to the surrounding tissues [7] and leads to disability among reproductive age women. Moreover, it represents a major personal and public health concern [8]. In humans, IFN- $\gamma$ or type II interferon (cytokine) is produced predominantly by natural killer (NK) and natural killer T (NKT) cells as part of the innate immune response, and by $\mathrm{CD} 4$ and $\mathrm{CD} 8$ cytotoxic $\mathrm{T}$ lymphocyte (CTL) effector T cells once antigen-specific immunity develops $[9,10]$. The IFN- $\gamma$ protein is encoded by the IFNG gene. IFN-gamma is encoded by a single gene mapped in humans to chromosome 12q24.1 [11]. Consequently, cytokines play a major role in the initiation, propagation and regulation of immune and inflammatory responses [12]. This immune response has been shown to play a significant role in the pathogenesis of endometriosis
[13]. A recent study reported that women with endometriosis have higher levels of IL-10, IFN-gamma, and IL-4, showing a shift toward increased inflammatory cytokines [14]. However, some studies have shown the concentration of IFN-gamma is decreased in peritoneal fluid in patients with endometriosis [15], although some groups have found no difference [16]. Enhanced levels of IFN gamma may be partly responsible for the impaired immunologic defense in endometriosis [17]. In spite of fluctuation in the levels of IFN gamma, associations have been suggested between the IFN-gamma CA-repeats polymorphism and multiple immunological disorders $[18,19]$. In support of polymorphism studies in Japanese patients with endometriosis [20], Kim et al suggested the $(\mathrm{CA})_{\mathrm{n}}$ repeat polymorphism in the IFN- $\gamma$ gene may be associated with a risk of endometriosis in the South Korean population. They have reported the most common allele composed of 13 repeats, followed by an allele of 15 repeats, and then by an allele of 12 repeats [21]. In contrast to these studies, our group previously demonstrated the increase in the "a12 (112bp) allele" in south Indian patients along with the significant association of IFNG gene CA-repeat polymorphism with endometriosis [22]. In view of the controversies and misgivings, we have revised the study with larger 
pollution size to explore the association between the IFNgamma gene (CA)-repeat polymorphisms and their possible impact on prevalence and pathophysiology of endometriosis with different stages in Indian population.

\section{Materials and Methods}

This is a prospective case-control study, which recruited women visiting the gynecology clinics at two collaborating centers, which register cases from all over the region of Andhra Pradesh, India complaining for infertility and suspected of having endometriosis on clinical grounds. During the period of our study (2006 2012), the samples from the consecutive women in these two centres were analyzed. Throughout the course of this study, we have recruited 792 patients coming for the diagnosis of infertility and other gynecological problems including endometriosis. Control group was excluded from these patients. The ethical committee of Hospital and Research Centre approved the research protocol. Informed written consent was obtained from all the participants. Proforma to obtain information on the general, obstetric and gynaecological details including family history, marital status, age at menarche, length of menstrual cycle, associated symptoms, duration and amount of blood loss, duration of infertility, and socio demographic details like social status, occupation, lifestyle, age, body mass index (BMI), limited information on diet was used and a thorough clinical examination done. General characteristics for all patients were recorded in detail in the medical chart. Apart from routine hematological investigations, hormone profiles, immunological assays, specialized investigations consisting of Pelvic ultrasound scan was done prior to surgery to know the uterine and ovarian status. Laparoscopy was performed as and when needed to confirm the diagnosis. All patients met the inclusion criteria: 18-39 years of age, having regular periods, residents of urban area since the last 20 years, absence of immunologic, hormonal disorders, or chronic diseases, experiencing chronic pelvic pain, dysmenorrhea $\&$ dyspareunia and presence of chocolate cyst on ultrasound scan or presence of endometriosis diagnosed by laparoscopy. Exclusion criteria were as follows: Women more than 39 years of age, proven female genital tuberculosis, pelvic inflammatory disease (PID), leiomyoma, adenomyosis, invasive carcinoma of the uterine cervix or ovarian cancer, diabetes, malnutrition and medical disorders like hypertension were excluded. The study population is from the state of Andhra Pradesh, which is known for ethnic variations.

\section{1. Study Group}

The study group consisted of 356 unrelated women of Indian origin, who were diagnosed to have endometriosis by laparoscopy. All these women are convene as per the standards of revised American Society for Reproductive Medicine scoring system, 1997 (rASRM, 1997) criteria [23]. All these women were infertile: primary infertility in $273(76.7 \%)$ women and secondary infertility in 83 (23.3\%) women with mean age of $29.78 \pm 6.11$ (age ranges: 18-39) years, mean age at menarche of $12.90 \pm$ 1.17 years, mean duration of infertility of $5.4 \pm 3.6$ years. The severity of endometriosis was assigned according to the rASRM scoring system. It incorporates number, size, location of endometrial implants, endometriomas, and/or adhesions as well as their morphology (red, white, and black) yielding a classification of four stages. 139 $(39.04 \%)$ women were clustered into minimal endometriosis (rASRM stage I), 121 (33.98\%) women into mild endometriosis (rASRM stage II), 58 (16.3\%) women in to moderate endometriosis (rASRM stage III), $38(10.67 \%)$ women in to severe endometriosis (rASRM stage IV), dyspareunia have been seen in $123(34.6 \%)$ women, dysmenorrhoea have in 145 (40.7\%) [i.e., mild in $110(31 \%)$, moderate in $18(5 \%)$ and severe in $17(4.8 \%)$ ] women. The remaining $88(24.72 \%)$ women were found asymptomatic.

\subsubsection{Control Group}

Three hundred and seventy two women were recruited from the same hospital for other gynaecological pathology (e.g., fibroids, tubal defects, polycystic ovaries, idiopathic infertility and pelvic inflammatory disease), tubal sterilization, and laparoscopically confirmed to be without endometriosis were included in the control group. Among these $249(66.94 \%)$ women were infertile: primary infertility in $215(57.8 \%)$ women, secondary infertility in $34(9.14 \%)$ women and $123(33.1 \%)$ women were proven fertile, with mean age of $29.2 \pm 3.4$ years, mean age at menarche of $12.7 \pm 1.0$ years and mean duration of infertility of $5.2 \pm 3.5$ years. We assume that substantial infertile control group may not prove any affect on the results. The following symptoms were also present in the control group: pelvic pain was observed in $149(40.1 \%)$ women, dyspareunia in $60(16.13 \%)$ women and dysmenorrhoea in $116(31.18 \%)$ women [i.e., mild 97 $(26.07 \%)$, moderate $19(5.11 \%)$ and there were no severe dysmenorrhoea cases]. The remaining 196 (52.69\%) women were symptom free. The Socio-demographic and clinical details of the endometriosis patients (Case group) versus control groups were given in the Table 1 .

Table 1: Socio-Demographic and Clinical Details of Endometriosis (Case group) and Control groups

\begin{tabular}{|c|c|c|}
\hline Characteristics & $\begin{array}{l}\text { Endometriosis } \\
\text { (Case) group } \\
\quad(\mathrm{n}=356)\end{array}$ & $\begin{array}{l}\text { Control } \\
\text { group } \\
(n=372)\end{array}$ \\
\hline Age (Years) * & $29.78 \pm 6.11$ & $\begin{array}{l}29.27 \pm \\
3.46\end{array}$ \\
\hline Age at menarche (Years) * & $12.90 \pm 1.17$ & $\begin{array}{c}12.74 \pm \\
1.07\end{array}$ \\
\hline Body mass index $(\mathrm{kg} / \mathrm{m} 2) *$ & $24.34 \pm 1.86$ & $24 \pm 1.35$ \\
\hline \multicolumn{3}{|l|}{ Symptoms } \\
\hline Duration of infertility (Years) * & $5.4 \pm 3.66$ & $5.24 \pm 3.53$ \\
\hline Primary infertility [n (\%)] & $273(76.7)$ & $215(57.8)$ \\
\hline Secondary infertility [n (\%)] & $83(23.3)$ & $34(9.14)$ \\
\hline Proven fertility $[\mathrm{n}(\%)]$ & NA & $123(33.1)$ \\
\hline Menstrual irregularity [n (\%)] & $89(25)$ & $37(9.95)$ \\
\hline Pelvic pain $[\mathrm{n}(\%)]$ & $324(91)$ & $149(40.1)$ \\
\hline Dyspareunia [n (\%)] & $123(34.6)$ & $60(16.13)$ \\
\hline Dysmenorrhoea [n (\%)] & $145(40.7)$ & $116(31.18)$ \\
\hline $\begin{array}{l}\text { No Dyspareunia \& } \\
\text { Dysmenorrhoea [n (\%)] }\end{array}$ & $88(24.72)$ & $196(52.69)$ \\
\hline
\end{tabular}

2.1.2. Genotype of IFN-gamma Gene 
DNA extraction: Genomic DNA was extracted from 6$8 \mathrm{ml}$ of EDTA anti-coagulated whole blood by using proteinase $\mathrm{K}$ digestion followed by a salting out method [24]. The genotype of the IFN-gamma CA-repeat gene deletion status of individuals were amplified by PCR using the primers described by Miyake et al. (2002) [18] with some modifications: forward (5'-TGA TTT TAT TCT TAC AAC ACA-3') and reverse (5'-CTT CCT GTA GGG TAT TAT TAT-3'). The 5' end of the forward primer was labeled with a fluorescent dye (6-Fam). An aliquot containing $25 \mathrm{ng}$ of genomic DNA was mixed with $0.4 \mathrm{mM}$ each primer, $0.2 \mathrm{mM}$ dNTPs, $1.5 \mathrm{mM} \mathrm{MgCl}_{2}, 1 \mathrm{X}$ reaction buffer $(1.5 \mathrm{mM})$ and $1.25 \mathrm{IU}$ of Taq polymerase (GENEI, Bangalore, India) in a total volume of $50 \mu \mathrm{l}$ of PCR buffer. The PCR procedure was as follows: an initial denaturation step at $95^{\circ} \mathrm{C}$ for $5 \mathrm{~min}$, and then 30 cycles of amplification at $94^{\circ} \mathrm{C}$ for $45 \mathrm{~s}, 48^{\circ} \mathrm{C}$ for $1 \mathrm{~min}$ and $72^{\circ} \mathrm{C}$ for $1 \mathrm{~min}$, followed by a final extension step at $72^{\circ} \mathrm{C}$ for $5 \mathrm{~min}$. The PCR products were denatured for $5 \mathrm{~min}$ at $94^{\circ} \mathrm{C}$, mixed with formamide-containing stop buffer, electrophoresed on a $6 \%$ polyacrylamide gel with an internal lane standard labeled with Genescan-500 Rox dye, and analyzed on an ABI Prism 3130 XL 16 capillary DNA sequencing system using Genescan analysis software (Applera International Inc., USA).

\section{Statistical Analysis}

Statistical analysis was performed using pantaray software systems [25]. Comparison of age, menarche age, body mass index, duration of infertility in the study groups and control group was performed using the independent two-sample Student's $\mathrm{t}$ test and data are presented as mean $\pm \mathrm{SD}$. The sample size required to detect a difference between two proportions for the IFNG CA-repeat polymorphisms was calculated using a computer program. The odds ratio (OR) and P-values were used to measure the strength of the association between allele frequencies and endometriosis. The disparity in the delivery of genotypes and allele frequencies of the IFN-gamma CA-repeat polymorphism between the controls and the patients with different stages of endometriosis were analyzed using the $\chi 2$ test as appropriate. All odds ratios (OR) were calculated as estimates of the confidence intervals (CI) were calculated at the $95 \%$ level $(95 \% \mathrm{CI})$.

\section{Results}

A total of 728 women were enrolled in the study, 356 cases and 372 controls. Among cases, there were 139 $(39.04 \%)$ women with stage I endometriosis, $121(33.98 \%)$ with stage II, 58 (16.3\%) with stage III, and 38 (10.67\%) with stage IV. Deep endometriotic nodules, dyspareunia were experimental in $123(34.6 \%)$ women, dysmenorrhoea in $145(40.7 \%)$ were observed, no significant difference in age, BMI age at menarche and duration of infertility was seen in between the two groups. Detailed sociodemographic characteristics and clinical details of endometriosis (Case group) and Control groups are described in Table 1. The prevalence of endometriosis was accounted in $48.9 \%$ (356) out of 728 total patients. Among infertile cases, $44.95 \%$ of women with endometriosis were specifically observed. There is no laparoscopic evidence of endometriosis seen in the control group and in the patients other gynecological problems. Seven diverse IFN-gamma alleles contained a sequence ranging from $10(108 \mathrm{bp})$ size to $16 \mathrm{CA}$ repeats $(120 \mathrm{bp})$ and were selected a10-a16 according to the number of CA repeats. The genotype and allele frequencies for the IFNgamma gene are summarized in Figure 1 and Table 2.

Table 2. Genotypes and allele frequencies of the a13 of IFNG CArepeat polymorphism in control women and Indian patients with different stages of endometriosis

\begin{tabular}{|c|c|c|c|c|c|}
\hline $\begin{array}{c}\text { Genotype } \\
\text { s \& } \\
\text { Alleles }\end{array}$ & $\begin{array}{c}\text { Control } \\
\text { group } \\
{[n=372} \\
(100 \%)]\end{array}$ & $\begin{array}{c}\text { rASRM } \\
\text { Stage }-\mathrm{I} \\
{[\mathrm{n}=139} \\
(39.04 \% \\
)]\end{array}$ & $\begin{array}{c}\text { rASRM } \\
\text { Stage - } \\
\text { II } \\
{[\mathrm{n}=121} \\
(33.98 \% \\
)]\end{array}$ & $\begin{array}{c}\text { rASRM } \\
\text { Stage - } \\
\text { III } \\
{[\mathrm{n}=58} \\
(16.3 \% \\
)]\end{array}$ & $\begin{array}{c}\text { rASR } \\
\text { M } \\
\text { Stage- } \\
\text { IV } \\
{[n=38} \\
(10.67 \\
\%)] \\
\end{array}$ \\
\hline $\begin{array}{c}\text { Genotype } \\
\text { a13: + /+ }\end{array}$ & $\begin{array}{c}91 \\
(24.46)\end{array}$ & $\begin{array}{c}49 \\
(35.25)\end{array}$ & $\begin{array}{c}44 \\
(36.36)\end{array}$ & $\begin{array}{c}19 \\
(32.76)\end{array}$ & $\begin{array}{c}13 \\
(34.21)\end{array}$ \\
\hline a13: + /- & $\begin{array}{c}149 \\
(40.05)\end{array}$ & $\begin{array}{c}51 \\
(36.69)\end{array}$ & $\begin{array}{c}45 \\
(37.19)\end{array}$ & $\begin{array}{c}24 \\
(41.38)\end{array}$ & $\begin{array}{c}16 \\
(42.10) \\
\end{array}$ \\
\hline a13:-/- & $\begin{array}{c}132 \\
(35.48) \\
\end{array}$ & $\begin{array}{c}39 \\
(28.05)\end{array}$ & $\begin{array}{c}32 \\
(26.45)\end{array}$ & $\begin{array}{c}15 \\
(26.86) \\
\end{array}$ & $\begin{array}{c}9 \\
(23.68) \\
\end{array}$ \\
\hline $\mathrm{Pb}=$ value & & 0.0437 & 0.0279 & 0.2552 & 0.2562 \\
\hline $\begin{array}{c}\text { Allele: } \\
\text { a13 }\end{array}$ & $\begin{array}{c}327 \\
(43.95)\end{array}$ & $\begin{array}{c}153 \\
(55.03)\end{array}$ & $\begin{array}{c}131 \\
(54.13)\end{array}$ & $\begin{array}{c}62 \\
(53.45)\end{array}$ & $\begin{array}{c}40 \\
(52.63)\end{array}$ \\
\hline Others & $\begin{array}{c}445 \\
(56.04) \\
\end{array}$ & $\begin{array}{c}125 \\
(44.96) \\
\end{array}$ & $\begin{array}{c}111 \\
(45.87)\end{array}$ & $\begin{array}{c}54 \\
(46.55) \\
\end{array}$ & $\begin{array}{c}36 \\
(47.37) \\
\end{array}$ \\
\hline $\mathrm{Pb}=$ value & & 0.00027 & 0.0013 & 0.0247 & 0.0845 \\
\hline $\begin{array}{c}\mathrm{OR}(95 \% \mathrm{C} \\
\mathrm{I}=)\end{array}$ & & $\begin{array}{l}1.665 \\
(1.26- \\
2.195)\end{array}$ & $\begin{array}{l}1.606 \\
(1.20- \\
2.147)\end{array}$ & $\begin{array}{c}1.56 \\
(1.056- \\
2.311)\end{array}$ & $\begin{array}{c}1.51 \\
(0.942- \\
2.425) \\
\end{array}$ \\
\hline
\end{tabular}

Note: $\mathrm{OR}=$ odds ratio; $\mathrm{CI}=$ confidence interval; rASRM- revised American Society for Reproductive Medicine (1997), The $\mathrm{P}^{\mathrm{b}}$ value was evaluated by $\chi^{2}$ test with a $2 \times 3$ contingency table (genotypes) and a $2 \times$ 2 table (allele frequencies) versus control women.

The comprehensive allele frequencies of the IFNgamma CA-repeat polymorphism in the healthy control women, patients with different stages of endometriosis and other clinical subgroups are demonstrated in Table 2. The global IFN-gamma allele frequencies in all patients with different stages of endometriosis was significantly dissimilar from that in the control women $(\chi 2=8.2690,4$ df, $\mathrm{P}=0.0822)$. The difference was due to an increase in the a13 (114 bp) allele in the patients with endometriosis $(\chi 2=13.23, \mathrm{p}=0.00027, \mathrm{OR}=1.6656,95.0 \% \mathrm{CI}=1.26$ $2.195)$. The slight increase of a13 allele over a12 allele is clearly shown in Figure 1 and Table 2.

This observation appears to be in contrast with the previous results published [22] may be due to the large sample size. Significant differences in overall allele frequencies were found between the control women and different stages of endometriosis are in the same line with Kim et al., 2011. The distribution of the IFN-gamma a13 genotypes was significantly diverse between patients with different stages of endometriosis and the control women $(\chi 2=6.2596,2 \mathrm{df}, \mathrm{p}=0.0437)$. The disparity was due to over-representation of the IFN-gamma a13 homozygote among the patients with different stages of endometriosis. An increased incidence of the IFN-gamma a13 allele was observed in different stages of endometriosis, these values were statistically significant with several assessments excluding the moderate to severe endometriosis stages. Differences are evident in the IFN-gamma a13 genotype and the allele frequencies between the groups with 
rASRM I, II, III and rASRM stage IV of endometriosis are statistically validated (Figure 1 and Table 2).

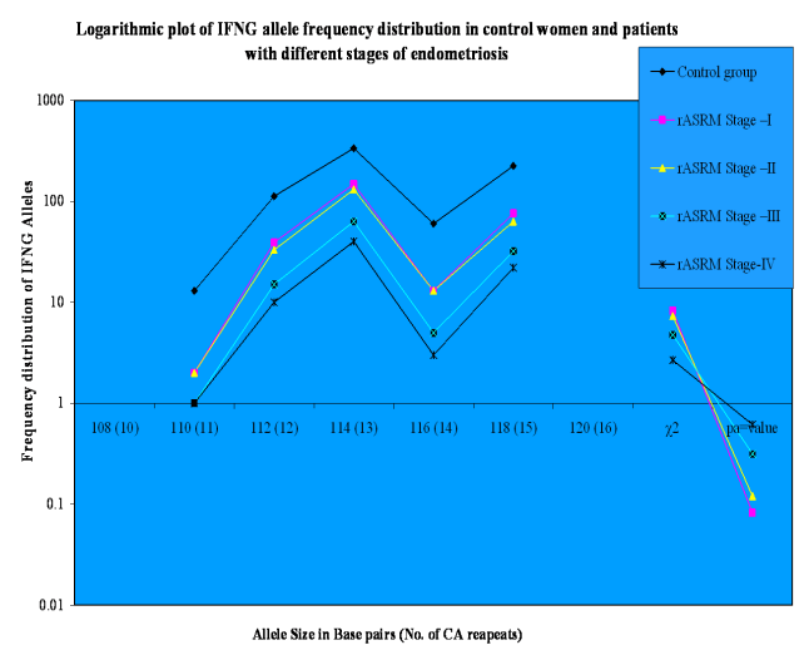

Figure 1. Logarithmic plot of IFNG allele frequency distribution in control women and patients with different stages of endometriosis

rASRM- revised American Society for Reproductive Medicine (1997), Stages (I to IV); $\mathrm{P}^{\text {a }}$ value $=$ the universal distribution of IFNG alleles between the control and the patients was evaluated with $\chi 2$ test with a $2 \mathrm{x}$ 7 contingency table. P-value $<0.05$ is considered significant.

\section{Discussion}

At the present, the cause of endometriosis and its natural history are still unknown, treatment options are limited, and there is no cure for this debilitating disease. It is estimated that endometriosis (at all stages) affects 10$15 \%$ of women in their reproductive age [26], 20-50\% of women with infertility [27], up to $45 \%$ in patients with chronic pelvic pain, 35-50\% in women with pain, infertility, or both [28]. The estimated prevalence of moderate to severe endometriosis is up to $2 \%$ [29] and 30 to $50 \%$ women with endometriosis are infertile [30]. It is reported that rectovaginal endometriotic nodules are strongly associated with pelvic pain and dysmenorrhea in $95 \%$ of cases, rectal dyschezia in $25 \%$ of cases and infertility [31]. The spontaneous progressive nature of this disease has been demonstrated in $30-60 \%$ of patients [32]. Cumulative recurrence rates after conservative surgery can be as high as $50-70 \%$ [33]. It is widely accepted that the endometriosis is an inflammatory process, associated with altered immune cell function, immune cell numbers, and elevated levels of inflammatory cytokines [34] including interferon-gamma, although in some studies the concentration of interferon-gamma is decreased in these patients. Nevertheless associations have been suggested to occur between interferon-gamma repeats polymorphism and multiple immunological disorders. However, the results remain controversial. In view of the inflammatory nature of the disease and role of IFN- $\gamma$ in the pathogenesis of disease [35], we sought to investigate the interferon- $\gamma$ gene (IFNG) CA-repeat polymorphisms in patients with different stages of endometriosis. This finding would confirm the role of polymorphisms in the immunological alterations and potential susceptibility of disease and encourage further research leading to the development of new counteractive modalities for the treatment of endometriosis. The results suggest that the frequency of the a13 polymorphism in the first intron of interferongamma is increased in large number of patients with different stages of endometriosis. In these endometriosis groups, the IFN-gamma a13 genotype and allele frequencies were found almost with substantial difference, regardless of whether or not the patients experienced complications of different clinical sub stages of the disease. The significant increase in the production of IFN$\gamma$ by peripheral blood mononuclear cells (PBMCs) is due to lack of the IFN- $\gamma$ a13 allele [18]. The reduced IFN- $\gamma$ secretion by peripheral blood $\mathrm{T}$ lymphocytes stimulated with phytohaemagglutinin (PHA), which may account for ectopic proliferation of endometrial cells [36]. Deficient local natural immunity against retrograde endometrium inoculation, an imbalance in cytokine production, defective T-cell IFN- $\gamma$ production, and a diminished number of NK cells may be the reasons for local proliferation of ectopic endometrial tissue [37]. It was claimed that the low level of IFN- $\gamma$ is accountable for tumor cell implantation, natural surveillance against cancer [38], cell maturation and intensification by the IFN-gamma CA-repeat polymorphism and prepares the patients toward susceptibility to different stages of endometriosis. Recent information demonstrating an autoimmune basis for endometriosis in a large percentage of sufferers may lead to new therapies aimed at modulating the immune response [39]. Further, the discovery of genes that influence treatment response may enable individualized treatment to be tailored on the basis of genotype [22]. The positive findings of this study are in support to the role of IFNG gene CA-repeats polymorphism in different stages. It is because of an increase in a13 repeats in minimal to mild endometriosis stage. Ethnicity, genetic constituents and climatic conditions might have limited the findings of this study.

\section{Conclusions}

In conclusion, the study therefore suggests that the polymorphism in interferon-gamma gene (IFNG) CArepeats are strongly associated with different stages of endometriosis in Indian patients. It is also suggested that the findings of this study can be one of the factors involved in the pathophysiology of endometriosis or rather a secondary event that occurs in a variety of inflammatory diseases. Additionally, it needs further investigation to see the reason behind the prevalence of interferon-gamma gene CA repeats polymorphism necessarily leading to the development of endometriosis.

\section{Acknowledgement}

We acknowledge the immense help received from the scholars whose articles are cited and included in references of this research article. The contributors of this article are also grateful to authors / editors / publishers of all those articles, journals and books from where the literature for this article has been snowballed, reviewed, incorporated and discussed in this current research article. We are also grateful to ICMR and UGC, Government of India for research funding. 


\section{Disclosure}

The authors have no competing interests.

\section{References}

[1] Wenzl R, Kiesel L, Huber JC, Wieser F. Endometriosis: a genetic disease. Drugs Today (Barc) 2003; 39:961-972.

[2] Halis G, Arici A. Endometriosis and inflammation in infertility. Ann N Y Acad Sci 2004; 1034:300-315.

[3] Bischoff F, Simpson JL. Genetic basis of endometriosis. Ann NY Acad Sci 2004; 1034:284-299.

[4] Vigano P, Somigliana E, Vignali M, Busacca M, Blasio AM. Genetics of endometriosis: current status and prospects. Front Biosci 2007; 12: 3247-3255.

[5] Matorras R, Rodriguez F, Pijoan JI, Etxanojauregui A, Neyro JL, Elorriaga MA, Rodriguez-Escudero FJ. Women who are not exposed to spermatozoa and infertile women have similar rates of stage I endometriosis. Fertil Steril 2001; 76:923-928.

[6] Vigano P, Parazzini F, Somigliana E, Vercellini P. Endometriosis: epidemiology and aetiological factors. Best Pract Res Clin Obstet Gynaecol 2004;18:177-200.

[7] Varma R, Rollason T, Gupta JK, Maher ER. Endometriosis and the neoplastic process. Reproduction 2004; 127:293-304.

[8] Jamieson DJ, Steege JF. The prevalence of dysmenorrhea, dyspareunia, pelvic pain, and irritable bowel syndrome in primary care practices. Obstet Gynecol 1996; 87:55-8.

[9] Schoenborn JR, Wilson CB. "Regulation of interferon-gamma during innate and adaptive immune responses". Adv. Immunol. 2007; 96: 41-101.

[10] Gray PW, Goeddel DV. "Structure of the human immune interferon gene". Nature. August 1982; 298 (5877): 859-63.

[11] Naylor SL, Sakaguchi AY, Shows TB, Law ML, Goeddel DV, Gray PW. "Human immune interferon gene is located on chromosome 12". J. Exp. Med. March 1983; 157 (3): 1020-7.

[12] Iwabe T, Harada T, Tsudo T, Nagano Y, Yoshida S, Tanikawa M, Terakawa N. Tumor necrosis factor-alpha promotes proliferation of endometriotic stromal cells by inducing interleukin- 8 gene and protein expression. J Clin Endocrinol Metab 2000; 85: 824-9.

[13] Lebovic DI, Mueller MD, Taylor RN. Immunobiology of endometriosis. Fertil Steril 2001; 75:1-10.

[14] Podgaec S, Abrao MS, Dias JA Jr, Rizzo LV, de Oliveira RM, Baracat EC Endometriosis: an inflammatory disease with a Th2 immune response component. Hum Reprod 2007; 22 (5):13731379.

[15] Hong-Nerng Ho, Ming-Yih Wu, Kuang-Han Chao, ChinDer Chen, Shee-Uan Chen, Hsin-Fu Chen, Yu-Shih Yang. Decrease in interferon gamma production and impairment of Tlymphocyte proliferation in peritoneal fluid of women with endometriosis. Am J Obstet Gynecol 1996; 175: 1236-1241.

[16] Keenan JA, Chen TT, Chadwell NL, Torry DS, Caudle MR. Interferon-gamma (IFN-gamma) and interleukin-6 (IL-6) in peritoneal fluid and macrophage-conditioned media of women with endometriosis. Am J Reprod Immunol 1994; 32: 180-183.

[17] Hsu CC, Yang BC, Wu MH, Huang KE. Enhanced interleukin- 4 expression in patients with endometriosis. Fertil Steril 1997; 67:1059-64.

[18] Miyake K, Nakashima H, Akahoshi M, Inoue Y, Nagano S, Tanaka Y, et al. Genetically determined interferon-gamma influences the histological phenotype of lupus nephritis. Rheumatology 2002; 41: 518-524.

[19] Ruiz-Linares A Dinucleotide repeat polymorphism in the interferon gamma (IFN-GAMMA) gene. Hum Mol Genet Sept. 1993; 2 (9): 1508.

[20] Kitawaki J, Koshiba H, Kitaoka Y, Teramoto M, Hasegawa G, Nakamura N, Yoshikawa T, Ohta M, Obayashi H and Honjo H. Interferon-gamma gene dinucleotide (CA) repeat and interleukin-4 promoter region $(-590 \mathrm{C} / \mathrm{T})$ polymorphisms in Japanese patients with endometriosis. Hum Reprod 2004; 19:1765-1769

[21] Kim J, Choi Y, Hwang S, Yoon S, Lee G, Chae S, Hwang K, Moon S. Association of the interferon- $\gamma$ gene (CA)n repeat polymorphism with endometriosis. BJOG 2011; 118:1061-1066.

[22] Rozati R, Vanaja MC, Nasaruddin K Genetic contribution of the interferon gamma dinucleotide-repeat polymorphism in South Indian women with endometriosis. J Obstet Gynaecol Res. 2010; $36(4): 825-31$.
[23] rASRM (1997) Revised American Society for Reproductive Medicine classification of endometriosis. Fertil Steril 1996; 67: 817-821.

[24] Miller SA, Dykes DD and Polesky HF. A simple salting out procedure for extracting DNA from human nucleated cells. Nucleic Acids Res 1988; 16:1215.

[25] Uitenbroek, Daan G, Binomial. SISA. 1997. http://www.quantitativeskills.com/sisa/distributions/binomial.htm. (1 Jan. 2004).

[26] Giudice LC, Tazuke SI, Swiersz L. Status of current research on endometriosis. J Reprod Med 1998; 43(Suppl 3):252-262.

[27] Gao X, Outley J, Botteman M, Spalding J, Simon JA, Pashos CL. Economic burden of endometriosis. 2006; 86:1561-1572.

[28] Ozkan S, Murk W, Arici A. Endometriosis and infertility: epidemiology and evidence-based treatments. Ann N Y Acad Sci 2008; 1127: 92-100.

[29] Zondervan KT, Cardon LR, Kennedy SH. What makes a good case-control study? Design issues for complex traits such as endometriosis. Hum Reprod 2002; 17:1415-1423. [PubMed: 12042253]

[30] Strdthy, J.H.. Molgaard, C.A., Coulam, C.B. and Melton, L.J. Endometriosis and infertility: a laparoscopic study of' endometriosis among fertile and infertile women. Fertil. Steril.,1982; 38, 667-672.

[31] Donnez J, Squifflet J. Laparoscopic excision of deep endometriosis. Obstet Gynecol Clin North Am 2004; 31:567-580.

[32] Olive DL, Lindheim SR, Pritts EA. Endometriosis and infertility: what do we do for each stage? Curr Womens Health Rep 2003; 3 : 389-394.

[33] Fedele L, Bianchi S, Di Nola G, Candiani M, Busacca M, Vignali M. The recurrence of endometriosis. Ann N Y Acad Sci 1994; 734:358-364.

[34] Agic A, Xu H, Finas D, Banz C, Diedrich K, Hornung D. Is endometriosis associated with systemic subclinical inflammation? Gynecol Obstet Invest. 2006; 62 (3): 139-147.

[35] Nishida M, Nasu K, Ueda T, Fukuda J, Takai N, Miyakawa I. Endometriotic cells are resistant to interferon-gamma-induced cell growth inhibition and apoptosis: a possible mechanism involved in the pathogenesis of endometriosis. Mol Hum Reprod. 2005; 11(1): 29-34.

[36] Krzysztof Szyllo, Henryk Tchorzewski, Malgorzata Banasik, Ewa Glowacka, Przemyslaw Lewkowicz, Anna Kamer-Bartosinska. The involvement of $\mathrm{T}$ lymphocytes in the pathogenesis of endometriotic tissues overgrowth in women with endometriosis. Mediators of Inflammation. June 2003; 12(3): 131-138.

[37] Hornung D, Klingel K, Dohrn K, Kandolf R, Wallwiener D, Taylor RN. Regulated on activation, normal T-cell-expressed and secreted mRNA expression in normal endometrium and endometriotic implants: assessment of autocrine/paracrine regulation by in situ hybridization. Am J Pathol 2001; 158: 1949 1954.

[38] Belardelli F, Ferrantini M. Cytokines as a link between innate and adaptive antitumor immunity. Trends Immunol 2002; 23: 201-208.

[39] Gajbhiye R, Suryawanshi A, Khan S, Meherji P, Warty N, Raut $\mathrm{V}$, Chehna N, Khole V. Multiple endometrial antigens are targeted in autoimmune endometriosis. Reprod Biomed Online 2008; 16: $817-24$. 